\title{
A Psicologia nos Contextos Institucionais
}

\author{
Psychology in Institutional Contexts
}

\section{La Psicología en el Contexto Institucional}

\author{
Gregorio Baremblitt ${ }^{1}$ \\ João Paulo Pereira Barros² \\ ${ }^{1}$ Instituto Gregorio Baremblitt, Belo Horizonte, MG, Brasil. $\quad{ }^{2}$ Universidade Federal do Ceará, Fortaleza, CE, Brasil. \\ Domenico Uhng Hur ${ }^{3}$ \\ ${ }^{3}$ Universidade Federal de Goiás, Goiânia, GO, Brasil.
}

O intuito deste número especial, composto por 13 artigos, é colocar em análise práticas e contextos institucionais nos campos da saúde, assistência social e direitos humanos de adolescentes e jovens, a partir de uma pluralidade de enfoques teórico-metodológicos na pesquisa em psicologia.

Vale destacar que essa inserção da psicologia em contextos institucionais é fruto do desenvolvimento de suas práticas durante os 58 anos de existência enquanto profissão. Consideramos que toda a mobilização e a campanha acerca de um compromisso social da psicologia e a ênfase da relação entre psicologia e políticas públicas forneceram as bases para que a articulação com distintos contextos institucionais fosse realizada com êxito.

Contudo, se realizarmos uma análise da história da psicologia, perceberemos que nem sempre foi assim. A psicologia é um saber disciplinar criado como aparato das elites sociais e que passou décadas numa perspectiva individualizante, ou cerrada em seus consultórios particulares e reforçando matrizes coloniais de poder-saber-subjetivação. Consideramos que essa virada em suas práticas se realizou na década de 1970, quando teorias e práticas psicológicas mais críticas passaram a ser ensinadas no país, bem como emergiu uma discussão mais politizada acerca das funções e relações de poder que nossa profissão assumia.

Desde seu começo, e não podia ser de outra maneira com uma disciplina enquadrada entre as ciências sociais e humanas, as práticas psicológicas que se foram produzindo nas instituições, organizações, estabelecimentos, agentes e serviços psicológicos tiveram e têm diversos e até antagônicos posicionamentos políticos. Num espectro que vai desde o serviço incondicional ao Estado, aos governos, às religiões e às diversas modalidades do capital até a militância, e situando-se num extremo, nos movimentos da luta armada revolucionária, passando por invenções críticas em cada um desses posicionamentos, a psicologia, que não pode ser senão política, veio para ficar.

Nesse sentido, a inserção da psicologia nos contextos institucionais se dá de diversas formas, amparada por distintos referenciais teóricos, posicionamentos políticos e dispositivos de investigação e intervenção. Atualmente, não se utilizam apenas os marcos teóricos clássicos da análise institucional e da psicologia institucional na leitura dos estabelecimentos (Baremblitt, 1986) e instituições concretas (Albuquerque, 1984; Hur, 2015), como os autores de referência René Lourau (1975), Georges Lapassade (1977), Franco Basaglia (1974), José Bleger (1980), Gregorio Baremblitt (1986), Marlene Guirado (1986), entre outros. Há uma ampliação do escopo teórico, valendo-se de uma leitura a partir das políticas públicas de saúde mental e/ou de segurança pública, bem como uma grande utilização de autores da filosofia. Dentre estes, destacam-se as marcantes presenças de Michel Foucault, Gilles Deleuze e Félix Guattari. Por outro lado, também são usadas referenciais que não necessariamente foram criadas para trabalhar os contextos institucionais, como perspectivas mais individualizantes da psicologia, ou mesmo teorias sociais que a princípio não utilizam as instituições como instâncias de análise. 
Nesse sentido, a inserção da Psicologia nos contextos institucionais é marcada por uma conexão de saberes que a torna uma disciplina de interface, ou que demanda que suas/seus autoras/es e pesquisadoras/es se posicionem num território de fronteira, produzindo bricolagens entre saberes que têm origens em campos diversos. Constitui-se assim um amplo campo permeado de práticas e saberes heterogêneos, e este número temático é uma expressão dessa heterogeneidade.

Dividimos esta edição especial em três conjuntos de artigos. Na primeira parte há sete textos que tratam de práticas e contextos institucionais de psicólogas e psicólogos em diversos âmbitos do campo da saúde.

Fundamentando-se na Psicologia Social Discursiva e a partir de uma pesquisa qualitativa com uso da observação participante e rodas de conversa, o artigo de abertura, Construção de Categorias/Lugares para a Loucura em Relatos de Usuários de Caps, objetiva investigar as categorias mobilizadas discursivamente por usuários de um Centro de Atenção Psicossocial (Caps I) para nomearem a si próprios e aos lugares sociais que constroem para eles e para as demais pessoas em sofrimento psíquico.

Na sequência, o artigo Na Casa e na Rua: Cenas dos Moradores de Serviços Residenciais Terapêuticos lança luzes sobre o agenciamento social da loucura, na perspectiva da desinstitucionalização. Trata-se de uma pesquisa de abordagem qualitativa, com inspirações etnográficas e orientação fenomenológica, realizada por meio da observação participante de cenas do cotidiano de moradores de Serviços Residenciais Terapêuticos (SRT) de uma cidade localizada na região Sudeste do Brasil.

O artigo denominado Processos de Subjetivação em Arte e Saúde Mental em um Manicômio Judiciário provém de uma pesquisa-intervenção realizada em um Hospital de Custódia e Tratamento Psiquiátrico (HCTP), objetivando cartografar processos de subjetivação em arte e saúde mental de pacientes no cotidiano do HCTP, além de mapear a produção de subjetividades custodiadas e seus efeitos nos modos de subjetivação de pacientes. Em sua análise, o texto ressalta que, nos processos de subjetivação dos "pacientes", há linhas de problematização dos modos de sujeição às instituições que agenciam a produção de subjetividades "custodiadas". Destaca, ainda, modos de resistência à produção de subjetividades custodiadas, principalmente, à excessiva medicalização e às grandes limitações na produção em saúde que atingem o HCTP.

$\mathrm{O}$ artigo As Oficinas Terapêuticas e a Lógica do Cuidado Psicossocial: Concepções dos(as) Coordenadores(as) objetiva compreender as concepções de um grupo de profissionais de saúde que coordenavam oficinas terapêuticas em um Caps a respeito dessa prática. Trata-se de um estudo clínico-qualitativo realizado em uma cidade do interior do estado de Minas Gerais, por meio de entrevista semiestruturada e diário de campo. Em suas análises, trabalha concepções sobre os objetivos e as especificidades das oficinas terapêuticas, bem como as concepções dos profissionais sobre a (não) adesão à referida prática.

Já em Percepção de Agentes Comunitários de Saúde Sobre uma Formação em Desenvolvimento Infantil e Indicadores de Risco, objetivou-se descrever a percepção de Agentes Comunitários de Saúde (ACS) de Porto Alegre acerca de uma formação teórico-prática sobre desenvolvimento infantil e indicadores de risco que visou a instrumentalização dos ACS para o uso do Indicadores Clínicos de Risco para o Desenvolvimento Infantil (Irdi). Metodologicamente, o estudo foi operacionalizado a partir da realização de grupos focais após cada módulo para avaliar a percepção dos ACS.

$\mathrm{O}$ artigo Atendimentos Psicológicos Breves em Instituições Públicas de Saúde: Contribuições do Existencialismo Sartriano expõe contribuições do existencialismo de Jean Paul Sartre para a prática de atendimentos psicológicos de curta duração em instituições públicas de saúde. Seus argumentos buscam mostrar que a proposta da psicanálise existencial realizada por Sartre e a utilização do método progressivo-regressivo não são restritas ao campo e à prática da psicoterapia tradicional, podendo contribuir para a realização de atendimentos psicológicos breves diante das demandas e queixas em instituições públicas de saúde.

O sétimo manuscrito, Internação Compulsória e Vida em Cena: Subjetividades em Descompasso, advém de uma pesquisa qualitativa com uso de entrevistas que enfocaram vidas submetidas à internação compulsória por meio de determinação judicial, em uma comunidade terapêutica de uma cidade do interior do Espírito Santo. Aponta, a partir da análise dos relatos dos participantes, estratégias de regulamentação da vida, seja pela judicialização, seja 
pela medicalização, de sujeitos que fogem da padronização dominante na lógica capitalista.

Além de artigos que interpelam o campo da saúde, o segundo bloco deste número especial comporta outros três trabalhos que focam práticas institucionais em contextos socioassistenciais.

É o caso do texto Habilidades Sociais e Acadêmicas de Crianças e Adolescentes em Instituições de Acolhimento, que considerando indicativos de dificuldades escolares de crianças e adolescentes com longo tempo de permanência em instituições, buscou comparar habilidades sociais, problemas de comportamento e desempenho escolar entre crianças/adolescentes com e sem histórico de acolhimento institucional. Trata-se do resultado de uma pesquisa com 36 crianças/adolescentes divididas em dois grupos: um com crianças de instituições de acolhimento do interior do estado do Mato Grosso do Sul e outro com crianças sem histórico de acolhimento e do mesmo contexto escolar, com seus respectivos docentes. Enquanto os participantes dos dois grupos responderam a inventários de habilidades sociais, conforme a idade, e ao Teste de Desempenho Escolar (TDE), os professores responderam a um de habilidades sociais e um de problemas comportamentais.

Já o manuscrito Instituições Residenciais Brasileiras para Idosos e Condições Psicológicas e Cognitivas de Residentes se trata de uma revisão integrativa que objetivou caracterizar Instituições de Longa Permanência para Idosos (Ilpi) brasileiras, em termos de condições de funcionamento e de oferta de serviços, bem como funções psicológicas e cognitivas de residentes, com base na literatura científica disponível nas bases SciELO, PePSIC e Periódicos Capes. A partir dessa análise, o artigo discute a necessidade de profissionais preparados para o trabalho com essa população, especialmente psicólogas e psicólogos capazes de intervir sobre o sofrimento psíquico de residentes.

Por sua vez, o ensaio teórico Práticas Cotidianas de Judicialização da Vida na Assistência Social visa problematizar a noção de judicialização da vida nas políticas públicas de assistência social, a partir de fragmentos de duas obras da literatura brasileira: "Vidas Secas", de Graciliano Ramos, e "Conto de Escola”, de Machado de Assis. Para tanto, ampara-se nos conceitos foucaultianos de governo e vontade de saber, assim como autoras/es brasileiras/os que trabalham com o tema, a fim de analisar o processo de desqualificação e criminalização de vidas. Com base nessa análise, o texto aponta pistas para resistir à judicialização no cotidiano da assistência social, tais como ações micropolíticas e criação de coletivos entre trabalhadores/as e usuárias/os.

No último bloco do número especial, há três artigos que pautam práticas institucionais na interface entre os campos dos direitos humanos de adolescentes e jovens.

$\mathrm{O}$ artigo Educação em Direitos Humanos na Perspectiva de Adolescentes Participantes de um Projeto Social objetiva discutir as interfaces entre psicologia e educação em direitos humanos a partir do relato de oficinas desenvolvidas com adolescentes participantes de um projeto social na região metropolitana de Porto Alegre. Para isso, a pesquisa utilizou a aplicação de questionários antes e depois da realização dos cinco encontros, além de diário de campo para o registro das informações em cada oficina, submetendo tais materiais à técnica da análise temática. Com base nisso, o artigo chama atenção para realidades de violação dos direitos humanos dos adolescentes e para as possibilidades de atuação da psicologia nesses contextos.

Considerando a proposta de emenda à Constituição (PEC 171/1993), em A Redução da Idade de Responsabilidade Criminal na Perspectiva de Adolescentes, objetiva-se investigar tal temática à luz da perspectiva de 25 adolescentes de escolas públicas, por meio de rodas de conversa, e outros cinco que estavam em cumprimento de medida socioeducativa, mediante entrevistas. $\mathrm{O}$ artigo destaca os seguintes analisadores que emergiram a partir das perspectivas de tais adolescentes: adolescência, raiva, medo, questão social, lei e violência.

Encerrando o número especial, figura o artigo $A$ Percepção da Experiência de Primeiro Aprisionamento em uma Unidade Prisional. Seu intuito é compreender como 61 detentos vivenciam o primeiro aprisionamento no sistema penitenciário e identificar os comportamentos adaptativos desencadeados a partir desse contexto. A amostra foi dividida em dois grupos (internos provisórios e internos sentenciados), para os quais foi utilizado um questionário sociodemográfico e criminal, bem como a técnica de evocação livre de palavras com os termos indutores "prisão" e "futuro". O estudo destaca a importância de que, a partir da perspectiva de sujeitos em situação de encarceramento, profissionais da saúde e de áreas afins possam identificar fatores de risco e de proteção 
que deem suporte na atenção e cuidados prestados à saúde física e mental das pessoas presas ou em condição de primeiro encarceramento.

Finalmente, gostaríamos de agradecer ao Conselho Federal de Psicologia, à editora da Revista Psicologia: Ciência e Profissão e àqueles e àquelas que contribuíram no processo de produção deste número especial. Em suma, se entendemos que uma psicologia inserida nos contextos institucionais se torna política, em última instância também pode ser considerada como uma "política psicológica", porque todo saber e fazer em seu modo o é. Dessa forma, convidamos a comunidade psicológica a pesquisar de maneira profunda, detalhada e o mais implicada possível o tema para adotar (ou mudar) consciente e plenamente a posição ético-política que se está assumindo no exercício da disciplina e na relação dela com todo o resto de seu programa existencial.

\section{Referências}

Albuquerque, J. A. G. (1986). Instituição e poder. A análise concreta das relações de poder nas instituições. Graal.

Baremblitt, G. F. (1986). Compêndio de análise institucional e outras correntes: Teoria e prática. Record.

Basaglia, F. (1974). A instituição da violência. In Tempo brasileiro, n. 35: As instituições e os discursos. Civilização Brasileira.

Bleger, J. (1980). Temas de psicologia: Entrevistas e grupos. Martins Fontes.

Guirado, M. (1986). Psicologia institucional. E.P.U.

Hur, D. U. (2015b). Axiomática do capital e instituições: abstratas, concretas e imateriais. Polis e Psique, 5(3), 156178. http://pepsic.bvsalud.org/pdf/rpps/v5n3/n5a10.pdf

Lapassade, G. (1977). Grupos, organizações e instituições. Francisco Alves.

Lourau, R. (1975). A análise institucional. Vozes.

\section{Gregório Baremblitt}

Médico psiquiatra, livre docente da Universidade Nacional de Buenos Aires, psicoterapeuta, analista institucional, esquizoanalista, esquizodramatista. Inventor do esquizodrama. Professor em três universidades argentinas e quatro universidades brasileiras. Autor de vários livros e artigos. Instituto Gregorio Baremblitt, Belo Horizonte - MG. Brasil. E-mail: baremblitt@gmail.com

(1) https://orcid.org/0000-0002-6433-5403

\section{João Paulo Pereira Barros}

Professor do Departamento de Psicologia e do Programa de Pós-Graduação em Psicologia da Universidade Federal do Ceará (UFC), Fortaleza - CE. Brasil.

E-mail: joaopaulobarros07@gmail.com

(1) https://orcid.org/0000-0001-7680-576X

\section{Domenico Uhng Hur}

Professor de graduação do Programa de Pós-Graduação em Psicologia da Universidade Federal de Goiás (UFG), Goiânia - GO. Brasil.

E-mail: domenicohur@hotmail.com

(1) https://orcid.org/0000-0002-6766-7024

Endereço para correspondência:

Faculdade de Educação da UFG. Curso de Psicologia. R. 235, s/n, Setor Leste Universitário. CEP: 74605-050.

Goiânia - GO. Brasil. 
Como citar: Baremblitt, G., Barros, J. P. P., \& Hur, D. U. (2021). A psicologia nos contextos institucionais. Psicologia: Ciência e Profissão, 41 (n.spe 4), 1-5. https://doi.org/10.1590/1982-3703003032020

How to cite: Baremblitt, G., Barros, J. P. P., \& Hur, D. U. (2021). Psychology in institutional contexts. Psicologia: Ciência e Profissão, 41 (n.spe 4), 1-5. https://doi.org/10.1590/1982-3703003032020

Cómo citar: Baremblitt, G., Barros, J. P. P., \& Hur, D. U. (2021). La psicología en el contexto institucional. Psicologia: Ciência e Profissão, 41 (n.spe 4), 1-5. https://doi.org/10.1590/1982-3703003032020 